\section{Dynamic versus Concurrent Lighting with Red and Blue Light-emitting Diodes as the Sole Light Source Can Potentially Improve Campanula Stock Plant Morphology for Cutting Production}

\author{
Devdutt Kamath and Yun Kong \\ School of Environmental Sciences, University of Guelph, 50 Stone Road East, \\ Guelph, ONN1G 2W1, Canada
}

\section{Chevonne Dayboll \\ Agriculture Development Branch, Ontario Ministry of Agriculture, Food and Rural Affairs, 4890 Victoria Avenue North, Vineland Station, ON LOR 2E0, Canada \\ Youbin Zheng \\ School of Environmental Sciences, University of Guelph, 50 Stone Road East, Guelph, ON N1G 2W1, Canada}

Additional index words. canopy height, cutting quality, indoor production, LEDs, lighting strategy, side branch

\begin{abstract}
Short campanula (Campanula portenschlagiana 'PGM Get MEE ${ }^{\text {, }}$ ) stock plants present a difficulty in machine-harvesting of cuttings. Light adjustment may be an effective approach to mediate plant elongation. Two experiments were performed to 1) investigate whether short-term (five weeks) daily 24-h dynamic lighting (DL) with red and blue light-emitting diodes (LEDs) can promote elongation without inducing flowering, and 2) explore whether DL can be used to modify stock plant morphology to improve the cutting quality and rooting success in a controlled environment. Two lighting treatments were used: concurrent lighting (CL) with red $(85 \%)$ and blue $(15 \%)$ LEDs (RB) at $100 \mu \mathrm{mol} \cdot \mathrm{m}^{-2} \cdot \mathrm{s}^{-1}$ and DL with red $\left(170 \mu \mathrm{mol} \cdot \mathrm{m}^{-2} \cdot \mathrm{s}^{-1}\right)$, blue (30 $\left.\mu \mathrm{mol} \cdot \mathrm{m}^{-2} \cdot \mathrm{s}^{-1}\right)$, and RB $\left(100 \mu \mathrm{mol} \cdot \mathrm{m}^{-2} \cdot \mathrm{s}^{-1}\right)$ LEDs sequentially at three different lighting stages, respectively, in both experiments. In Expt. 1, at final harvest of stock plants, the side branches were longer under DL compared with CL, but the five $(=2+2+1)$ weeks of 24-h daily lighting resulted in visible flower buds under both treatments. Based on the results of Expt. 1, a second experiment (Expt. 2) was conducted with the same cultivar and experimental conditions, but with a shorter photoperiod $\left(10 \mathrm{~h} \cdot \mathrm{d}^{-1}\right)$ for $11(=8+2+$ 1) weeks. In Expt. 2, at final harvest, DL compared with $C L$ caused more upright side branches, and reduced the dry biomass of side branches with one branching order and leaf chlorophyll content. However, the harvested cutting quality and rooting success were similar between both treatments. In both experiments, side branch number under DL was greater compared with $C L$ at the end of the first lighting stage. Stock plants under DL were taller from the second lighting stage on to final harvest compared with $C L$, and the final heights of stock plants under DL met the target for machine-harvest in both experiments. Therefore, if the lighting strategy is further optimized, DL can potentially benefit controlled-environment production of campanula cuttings.
\end{abstract}

Campanula (Campanula portenschlagiana), also called bellflower, is a commercially important ornamental potted plant. Most commercial growers prefer to use cuttings for propagating bellflower since this method can maintain stock plant quality characteristics and reduce the propagation time compared with seed propagation (Christiaens et al., 2016). Machine-harvesting of cuttings has the potential to replace manual harvest to reduce labor costs and improve efficiency (Adegbola et al., 2019). However, campanula stock plants that are too short or compact present a challenge for morphology for different production purposes, especially in controlled environments (Clifford et al., 2004; Mah et al., 2018; Moe et al., 1991).

Controlled environment facilities equipped with electric light as sole-source lighting (SSL) have been increasingly used for commercial plant production (Mitchell and Stutte, 2017). However, there is a lack of information on their use for the production and maintenance of stock plants for cutting production. Light-emitting diodes (LEDs) are replacing traditional light sources (e.g., high-pressure sodium and fluorescent lights) as SSL in controlled environment plant production because of their many advantages such as adjustable light spectra (Mitchell and Stutte, 2017; Zheng, 2016). For bichromatic LED lighting, a red (R) and blue (B) spectral combination (RB-LED) has been commonly used in horticultural crop production (Davis and Burns, 2016), as these spectra are readily absorbed and utilized for photosynthesis (McCree, 1972). For RB-LED lighting, a common photon flux ratio of R:B at $\approx 85: 15$ has been used for bedding plants (Randall and Lopez, 2014), as well as potted campanula plants (Ouzounis et al., 2014, 2018). In controlled environments, under RB-LED as SSL, plants display a compact canopy with thick shoots and dark-colored leaves (Kim and Hwang, 2019; Randall and Lopez, 2014, 2015), possibly because $R$ and $B$ trigger high activity of both phytochrome and cryptochrome (Casal and Mazzella, 1998; Demotes-Mainard et al., 2016). If machine-harvest of cuttings is intended, RB-LED may not be suitable for growing campanula stock plants in controlled environments as SSL.

Our recent studies in controlled environments with SSL indicate that narrow-band R and B LED light at moderate levels (e.g., 100 $\left.\mu \mathrm{mol} \cdot \mathrm{m}^{-2} \cdot \mathrm{s}^{-1}\right)$ can cause contrasting morphological responses, at least due to their different phytochrome photostationary state (PPS), which is much higher ( 0.89 vs. 0.49$)$ for $R$ than B (Kong et al., 2018, 2019a). For many species, narrow-band B LED light can increase stem elongation, induce earlier flowering, and reduce side branching, by promoting the shade-avoidance response (Kong et al., 2018, 2019b). By contrast, narrow-band R LED light can inhibit stem elongation, delay flowering, and increase branching, by preventing the shade-avoidance response (Kong and Zheng, 2020; Kong et al., 2018). However, the contrasting morphological responses to $\mathrm{R}$ and $\mathrm{B}$ were not observed in campanula stock plants under LED lighting at $100 \mu \mathrm{mol} \cdot \mathrm{m}^{-2} \cdot \mathrm{s}^{-1}$, but at a lower intensity (unpublished data). In addition to light spectra (e.g., R and B), light intensity can also affect plant morphology (Johnson et al., 2020; Jones-Baumgardt et al., 2019). For most species, increasing light intensity leads to a shorter and thicker stem, more side branches, and darker leaf color (Craver et al., 2018; Gerovac et al., 2016; Kong and Zheng, 2019). It appears that a combination of light spectra and intensity is necessary to regulate campanula stock plant morphology. Taking into account the ideal morphology of campanula stock plants and the results of previous studies, it may be feasible to use high-intensity R LED 
Table 1. Environmental data for the different lighting treatments: Concurrent lighting (CL) or dynamic lighting (DL) of red and blue light-emitting diodes.

\begin{tabular}{|c|c|c|c|c|c|c|c|c|}
\hline $\begin{array}{l}\text { Lighting } \\
\text { treatment }\end{array}$ & $\begin{array}{l}\text { Lighting } \\
\text { stage }\end{array}$ & $\begin{array}{l}\text { Light spectral } \\
\text { quality }\end{array}$ & $\begin{array}{c}\text { PPFD } \\
\left(\mu \mathrm{mol} \cdot \mathrm{m}^{-2} \cdot \mathrm{s}^{-1}\right)\end{array}$ & $\begin{array}{c}\text { DLI } \\
\left(\mathrm{mol} \cdot \mathrm{m}^{-2} \cdot \mathrm{d}^{-1}\right)\end{array}$ & $\begin{array}{c}\text { Total R } \\
\text { amount }\left(\mathrm{mol} \cdot \mathrm{m}^{-2}\right)\end{array}$ & $\begin{array}{l}\text { Total B amount } \\
\left(\mathrm{mol} \cdot \mathrm{m}^{-2}\right)\end{array}$ & Air temp. $\left({ }^{\circ} \mathrm{C}\right)$ & RH (\%) \\
\hline \multicolumn{9}{|c|}{ Expt. 1 (24-h photoperiod) } \\
\hline $\mathrm{CL}$ & - & $\mathrm{RB}^{\mathrm{z}}$ & $102.2 \pm 0.2^{\mathrm{y}}$ & $8.8 \pm 0.01$ & $260.8 \pm 0.7$ & $47.3 \pm 0.1$ & $21.0 \pm 0.04$ & $67.5 \pm 3.6$ \\
\hline \multirow{2}{*}{ DL } & 2 & B & $29.6 \pm 0.05$ & $2.6 \pm 0.004$ & \multirow[t]{2}{*}{$261.0 \pm 0.4$} & \multirow[t]{2}{*}{$45.2 \pm 0.1$} & $21.1 \pm 0.02$ & $64.5 \pm 3.1$ \\
\hline & 3 & $\mathrm{RB}$ & $102.1 \pm 0.7$ & $8.8 \pm 0.1$ & & & $21.2 \pm 0.1$ & $64.8 \pm 2.0$ \\
\hline \multicolumn{9}{|c|}{ Expt. 2 (10-h photoperiod) } \\
\hline \multirow{2}{*}{ DL } & 2 & B & $31.7 \pm 0.3$ & $1.1 \pm 0.01$ & \multirow[t]{2}{*}{$366.0 \pm 0.9$} & \multirow[t]{2}{*}{$20.0 \pm 0.1$} & $21.1 \pm 0.01$ & $70.4 \pm 0.2$ \\
\hline & 3 & $\mathrm{RB}$ & $102.0 \pm 0.4$ & $3.7 \pm 0.01$ & & & $21.0 \pm 0.001$ & $70.2 \pm 0.07$ \\
\hline
\end{tabular}

${ }^{\mathrm{z}} \mathrm{RB}=85 \%$ red and $15 \%$ blue at $\approx 100 \mu \mathrm{mol} \cdot \mathrm{m}^{-2} \cdot \mathrm{s}^{-1} ; \mathrm{R}=100 \%$ red at $\approx 170 \mu \mathrm{mol} \cdot \mathrm{m}^{-2} \cdot \mathrm{s}^{-1} ; \mathrm{B}=100 \%$ blue at $\approx 30 \mu \mathrm{mol} \cdot \mathrm{m}^{-2} \cdot \mathrm{s}^{-1}$.

${ }^{\mathrm{y}}$ Data are means $\pm \mathrm{SE}(\mathrm{n}=3)$.

PPFD = photosynthetic photon flux density; DLI = daily light integral; $\mathrm{RH}=$ relative humidity.

light first to increase side branching while inhibiting flowering; then to use low-intensity B LED light to promote side branch elongation; and finally, to use moderate-intensity RBLED light to increase side branch diameter and leaf greenness. This dynamic lighting at three stages may be an effective lighting strategy to grow campanula stock plants for cutting production.

For dynamic lighting using $\mathrm{R}$ and $\mathrm{B}$ LEDs, previous studies on the plant morphological responses have been reported mainly on lettuce (Lactuca sativa). Alternating $\mathrm{R}$ and $\mathrm{B}$ light at $120 \mu \mathrm{mol} \cdot \mathrm{m}^{-2} \cdot \mathrm{s}^{-1}$ for $12 \mathrm{~h}$ each (i.e., 24-h lighting) compared with concurrent $\mathrm{R}$ and $\mathrm{B}(\mathrm{RB})$ at $120 \mu \mathrm{mol} \cdot \mathrm{m}^{-2} \cdot \mathrm{s}^{-1}$ (i.e., $240 \mu \mathrm{mol} \cdot \mathrm{m}^{-2} \cdot \mathrm{s}^{-1}$ total) for $12 \mathrm{~h}$ or at $60 \mu \mathrm{mol} \cdot \mathrm{m}^{-2} \cdot \mathrm{s}^{-1}$ (i.e., 120 $\mu \mathrm{mol} \cdot \mathrm{m}^{-2} \cdot \mathrm{s}^{-1}$ total) for $24 \mathrm{~h}$ increased FW, DW, and stem length of lettuce (Kuno et al., 2017). Ohtake et al. (2018) found that alternating R and B at 120 and $40 \mu \mathrm{mol} \cdot \mathrm{m}^{-2} \cdot \mathrm{s}^{-1}$, respectively, for $12 \mathrm{~h}$ each increased plant height and DW of lettuce compared with RB at 60 and $20 \mu \mathrm{mol} \cdot \mathrm{m}^{-2} \cdot \mathrm{s}^{-1}$ (i.e., 80 $\mu \mathrm{mol} \cdot \mathrm{m}^{-2} \cdot \mathrm{s}^{-1}$ total) for $24 \mathrm{~h}$, respectively. Lettuce grown under alternating $\mathrm{R}$ at $100 \mu \mathrm{mol} \cdot \mathrm{m}^{-2} \cdot \mathrm{s}^{-1}$ and $B$ at $60 \mu \mathrm{mol} \cdot \mathrm{m}^{-2} \cdot \mathrm{s}^{-1}$ for $12 \mathrm{~h}$ each (i.e., 24-h lighting) had increased FW, DW, and leaf length and width compared with $\mathrm{RB}$ for $12 \mathrm{~h}$ at the same respective intensities (Shimokawa et al., 2014). In the aforementioned studies, although dynamic

Received for publication 2 June 2021. Accepted for publication 7 Sept. 2021.

Published online 21 October 2021

This project is part of the Accelerating Green Plant Innovation for Environmental and Economic Benefit Cluster and is funded by the Canadian Ornamental Horticulture Alliance (COHA-ACHO) and by the Government of Canada under the Canadian Agricultural Partnership's AgriScience Program. We thank Plusrite Hortscience for their financial support, Lumigrow Inc. for providing LED light fixtures, and Sunrise Greenhouses Ltd. for providing plant materials and advice. Thanks to Theo Blom for the informative discussions and editing the manuscript. Thanks to Michelle Edwards for her help with statistical analysis and Dave Llewellyn for his excellent technical support and informative discussions during the study.

Y.Z. is the corresponding author. E-mail: yzheng@uoguelph.ca.

This is an open access article distributed under the CC BY-NC-ND license (https://creativecommons. org/licenses/by-nc-nd/4.0/). compared with concurrent lighting with $\mathrm{R}$ and $\mathrm{B}$ LEDs promoted growth (e.g., elongation and biomass production) of lettuce plants, the $\mathrm{R}$ and $\mathrm{B}$ lighting was repeatedly alternated in a daily cycle. This way of alternating light for plant growth is totally different from dynamic lighting with $\mathrm{R}$ and $B$ LEDs at three different stages in a production cycle. However, the information related to such a lighting strategy has so far been unavailable especially for growing campanula stock plants in controlled environments.

Our previous studies have shown that under 24-h lighting, B LED had a greater promotion effect on plant elongation compared with <24-h lighting (Kong et al., 2019a). In controlled environments, continuous (24-h) lighting at a low to moderate intensity is a way of producing crops economically (Sysoeva et al., 2010). Under natural conditions, a longer vs. shorter photoperiod can promote flowering of campanula plants, and this species is considered a long-day plant (LDP) by some growers. However, accumulating evidence has indicated that light spectra can affect flowering in a pathway independent from photoperiod, despite a crosstalk between them (Putterill et al., 2004; Simpson and Dean, 2002; Thomas, 2006). For example, in a controlled environment under 24$\mathrm{h}$ SSL, R and RB-LED delayed flowering of two LDPs compared with B (Kong et al., 2018). Besides light spectra and photoperiod, a low daily light integral (DLI) can also inhibit or delay the flowering of campanula (Kjaer et al., 2011; Niu et al., 2001). Even if at a 24-h photoperiod, the average DLI in controlled environments would be less than $9 \mathrm{~mol} \cdot \mathrm{m}^{-2} \cdot \mathrm{d}^{-1}$ due to low to moderate light intensities (e.g., 100 $\mu \mathrm{mol} \cdot \mathrm{m}^{-2} \cdot \mathrm{s}^{-1}$ ). Furthermore, a previous study on a long-day campanula species (Campanula isophylla) indicated that only after more than 6-8 weeks of long-day treatments, visible flower buds started to appear on stock plants (Moe, 1976). Possibly, <6 (e.g., 5) weeks of 24-h lighting would not result in visible flower buds on campanula stock plants for cutting harvest.

To examine a dynamic lighting strategy on campanula, not only would stock plant morphology (e.g., plant height, side branch number, length and thickness, and leaf color) need to be observed, but harvested cutting quality (e.g., length, thickness, and rooting) could be important plant traits for evaluation. In addition to enabling machine-harvesting, the purpose of adjusting stock plant morphology through lighting is to eventually produce a large number of high-quality cuttings. Based on all the above information, we hypothesized that a dynamic lighting strategy with $\mathrm{R}$ and $\mathrm{B}$ LEDs compared with concurrent lighting (i.e., RBLED) can improve campanula stock plant morphology for cutting harvest in a controlled environment as SSL. The objectives of this study were (1) to investigate whether short-term (e.g., 5-week) dynamic lighting at a 24 -h photoperiod can be used to promote campanula stock plant elongation without inducing flowering, and (2) to explore whether dynamic lighting can be applied to adjust stock plant morphology of campanula to improve cutting quality and rooting in a controlled environment.

\section{Materials and Methods}

Expt. 1: Examining whether short-term 24-h dynamic lighting can promote elongation growth without inducing flowering

Plant materials and growing conditions. The experiment was conducted in a $29 \mathrm{~m}^{2}$ walk-in growth chamber at the University of Guelph, Guelph, ON, Canada from July to Aug. 2019. Campanula 'PGM Get MEE' ${ }^{\circledR}$ (Campanula portenschlagiana) plants $(\approx 6-7$ weeks old) were provided as plugs by a local grower (Sunrise Greenhouses Ltd., Vineland Station, ON, Canada). Before lighting treatments, plugs were transplanted into $8.5 \times 8.5 \times$ $10 \mathrm{~cm}$ pots (one plant per pot) containing a peat-perlite mix (Sunshine Mix \#1; Sun Gro Horticulture, Agawam, MA). Then the potted plants were put into supporting trays $(27 \times$ $56 \times 5 \mathrm{~cm}$ ). For each replicate, there was one tray per lighting treatment, which contained eight plants. The plants were subirrigated with a nutrient solution described in Kong et al. (2019b) every 2-3 d as needed until plant harvesting. The target air temperature and relative humidity (RH) were set at $21^{\circ} \mathrm{C}$ and $75 \%$, respectively, and were controlled by an Argus control system (Argus Controls Systems Ltd., Surrey, BC, Canada). Data loggers (Onset HOBO U12-013; Onset Computer Corporation, Bourne, MA) were also used to record the 
actual values of air temperature and RH every 5 min (Table 1).

Experimental design and treatments. Two lighting strategies were adopted for lighting treatments as follows. (1) Concurrent lighting of $\mathrm{R}$ and B LEDs (CL). Throughout the whole experimental period, plants were exposed to the same lighting with a combination of $85 \% \mathrm{R}$ and 15\% B LED light (RB) at a photosynthetic photon flux density (PPFD) of $\approx 100$ $\mu \mathrm{mol} \cdot \mathrm{m}^{-2} \cdot \mathrm{s}^{-1}$. (2) Dynamic lighting of $\mathrm{R}$ and B LEDs (DL). Plants were grown under different lighting at three stages: $\mathrm{R}$ at $\approx 170$ $\mu \mathrm{mol} \cdot \mathrm{m}^{-2} \cdot \mathrm{s}^{-1}$ for the first lighting stage, $\mathrm{B}$ at $\approx 30 \mu \mathrm{mol} \cdot \mathrm{m}^{-2} \cdot \mathrm{s}^{-1}$ for the second lighting stage, and $\mathrm{RB}$ at $\approx 100 \mu \mathrm{mol} \cdot \mathrm{m}^{-2} \cdot \mathrm{s}^{-1}$ for the final lighting stage. The three lighting stages of DL lasted 2, 2, and 1 weeks, respectively. All treatments in Expt. 1 were on a 24-h photoperiod, and the average DLI was $\approx 8.8$ $\mathrm{mol} \cdot \mathrm{m}^{-2} \cdot \mathrm{d}^{-1}$ for both treatments in Expt. 1 (Table 1). The experiment was conducted as a randomized complete block design with one factor (lighting strategy) and three replicates (i.e., blocks). The three blocks were located in three sections of the chamber, and the above two lighting treatments were randomly allocated to two separate compartments within each of the three blocks. The compartments in the chamber were divided by opaque white curtains to prevent neighboring light effects. The LED fixtures (ProSeries 325; LumiGrow Inc., Emeryville, CA) had two channels with peak wavelengths of $440 \mathrm{~nm}$ and $661 \mathrm{~nm}$ for B

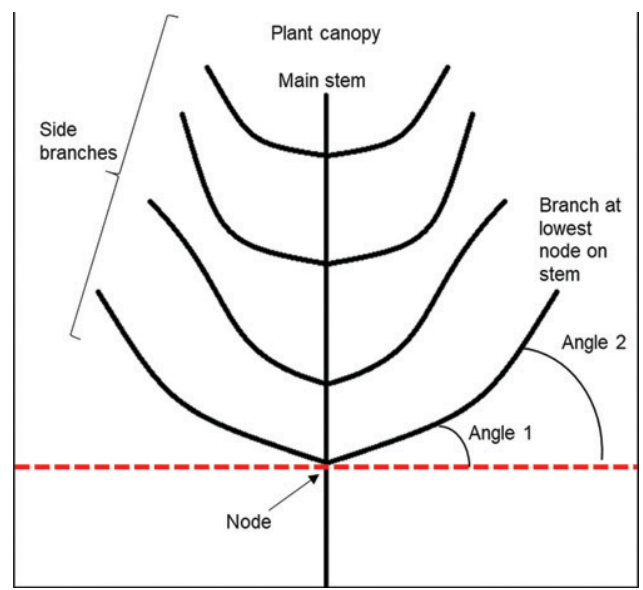

Fig. 1. Diagram of measuring two inclination angles of the lowest side branch (SB) from main stem. The lowest SBs of sampled plants were traced onto a sheet of A4 white paper, and SB angles were measured with a protractor.

and $\mathrm{R}$, respectively. Light spectra and intensities were measured using a radiometrically calibrated spectrometer (UV/Vis-Flame-S-XR; Ocean Optics, Inc., Dunedin, FL) coupled to a CC3 cosine corrector with a $1.9 \mathrm{~m} \times 400 \mu \mathrm{m}$ optical fiber. All light fixtures were hung at a height of $80 \mathrm{~cm}$ above the bench.

Growth and morphology measurements. Canopy height from the medium to the highest point of the plant and the number of side branches $(\mathrm{SB})(>1 \mathrm{~cm})$ on the main stem of each plant in each plot were nondestructively investigated weekly from the start of lighting treatments until the final harvest. After 5 weeks of lighting treatments, nine plants were randomly sampled from each treatment and harvested for morphological observations and biomass determination. For each harvested plant, three leaves were randomly selected for measurement of chlorophyll content index (CCI) using a chlorophyll meter (CCM-200; Opti-Sciences Inc., Hudson, NH). The plants were then cut at the substrate surface and all SBs with intact leaves were separated from the main stem. The length of the main stem and the heights of the lowest and
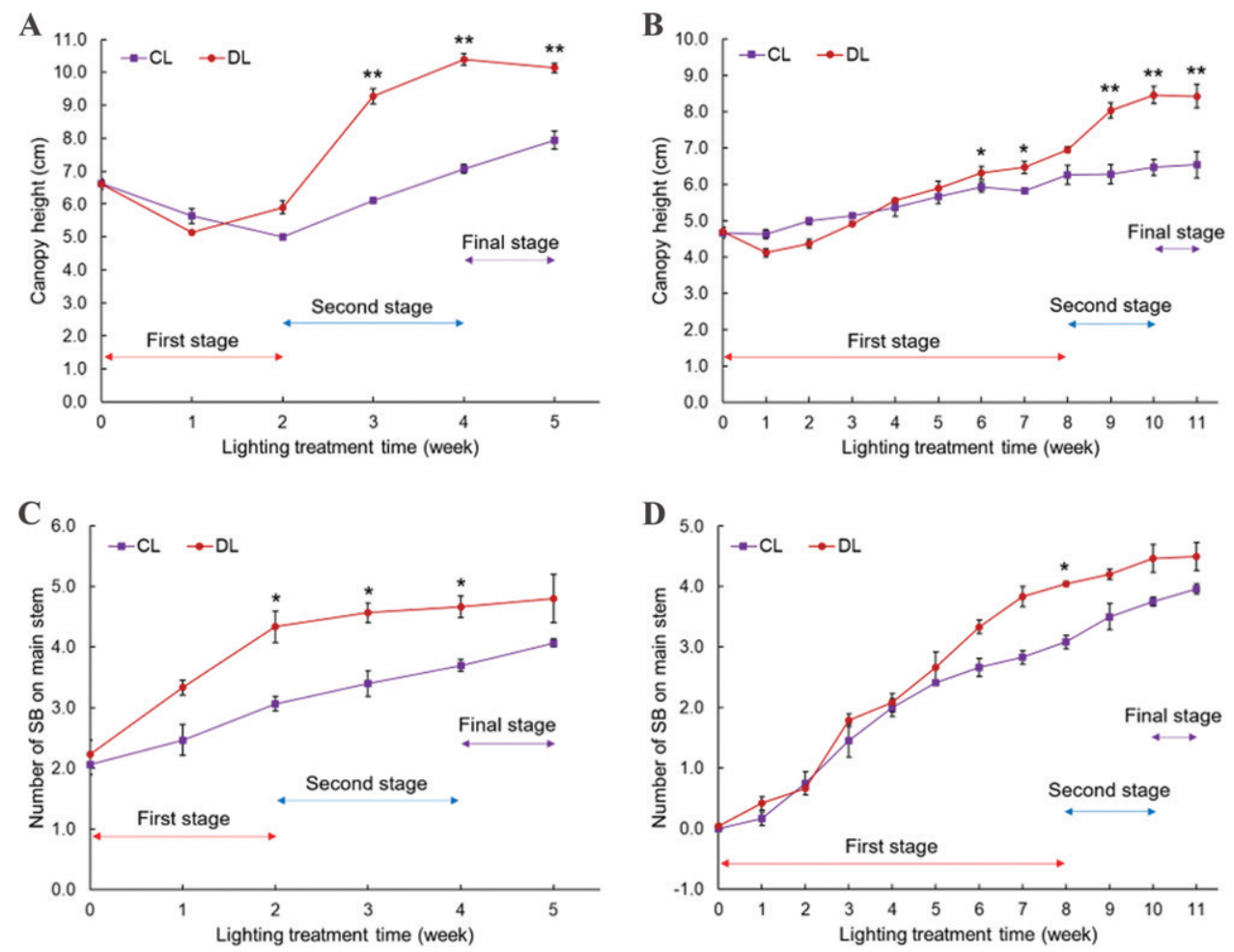

Fig. 2. Weekly variation of canopy height $(\mathrm{cm})$ and side branch $(\mathrm{SB})$ number on the main stem of campanula stock plants grown under different lighting treatments in Expt. $1(\mathbf{A}, \mathbf{C})$ and Expt. $2(\mathbf{B}, \mathbf{D})$. Data are mean $\pm \mathrm{SE}(\mathrm{n}=3)$. For the two treatments, CL was concurrent lighting of red $(85 \%)$ and blue (15\%) light-emitting diodes (LEDs) (RB) at $100 \mu \mathrm{mol} \cdot \mathrm{m}^{-2} \cdot \mathrm{s}^{-1}$, and DL was dynamic lighting of red $\left(170 \mu \mathrm{mol} \cdot \mathrm{m}^{-2} \cdot \mathrm{s}^{-1}\right), \mathrm{blue}\left(30 \mu \mathrm{mol} \cdot \mathrm{m}^{-2} \cdot \mathrm{s}^{-1}\right)$, and RB $\left(100 \mu \mathrm{mol} \cdot \mathrm{m}^{-2} \cdot \mathrm{s}^{-1}\right)$ LEDs sequentially at three different lighting stages, respectively. A photoperiod of 24 and $10 \mathrm{~h} \cdot \mathrm{d}^{-1}$ was used for both treatments in Expt. 1 and Expt. 2, respectively. In each experiment, for each week, no symbol on the points indicate that the two treatments are not significantly different at $P \leq 0.05$ level, but *, **, or *** indicate a significant difference at $P \leq 0.05,0.01$, or 0.001 level, respectively, according to Tukey's honestly significant difference test. 
highest nodes producing SBs on the main stem were measured with a ruler. Main stem diameter was determined using a digital caliper. The length and diameter of each SB were determined using a ruler and digital caliper, respectively. The longest SB's length and diameter were identified, and average length and diameter of individual SB were calculated for each plant. Then the main stem and all SBs of each harvested plant were placed in separate paper bags and dried at $90^{\circ} \mathrm{C}$ to constant weight to determine dry weight (DW). For each sampled plant, DW of the main stem and all SBs were measured separately, and then the aboveground DW was calculated. The number of potentially marketable cuttings per plant was determined based on the investigation of all SBs harvested from each stock plant with characteristics of a standard quality cutting such as four to five true leaves and at least $2.5-\mathrm{cm}$ stem length (Commercial greenhouse grower, personal communication). The percentage of potentially marketable cuttings relative to total SB number from each stock plant was also calculated.

\section{Expt. 2: Exploring a strategy of dynamic} lighting to adjust stock plant morphology for harvesting quality cuttings

The second experiment (Expt. 2) was conducted from Oct. to Dec. 2019 in the same growth chamber as that in Expt. 1. Plant materials and growing conditions, experimental design and treatments, and growth and morphology measurements were the same as reported in Expt. 1 unless otherwise stated. In Expt. 2, both treatments used a photoperiod of $10 \mathrm{~h} \cdot \mathrm{d}^{-1}$ ( 0900 to $1900 \mathrm{HR}$ ) for all three lighting stages, and for DL lighting, exposure time of each stage was based on the target values of SB number and height reached at the end of each lighting stage in Expt. 1. The three lighting stages of DL lasted 8,2, and 1 weeks, respectively, and the average DLI was $3.7 \mathrm{~mol} \cdot \mathrm{m}^{-2} \cdot \mathrm{d}^{-1}$ for both treatments (Table 1).

In Expt. 2, 15 plants were sampled from each treatment for morphological observations and biomass determination. After the sampled plants were cut at the substrate surface, the inclination angles of SB at the lowest node on the main stem were measured for each plant to evaluate the degree of shoot hyponasty (i.e., upward growth). To determine the SB inclination angles, plants were laid on a white sheet of A4 paper, and the main stems with the lowest SBs were traced to measure the angles using a protractor (Fig. 1). These harvested plants were separated into main stem and SBs, and the traits were measured following nearly the same protocol as mentioned in Expt. 1. The exception was that the SBs with only one branching order and those with more than one branching order were separately investigated for each plant. The remaining nine plants from each treatment were used for evaluation of cutting quality and rooting. From each plant, seven to 10 cuttings were harvested as the shoot tips with four to five true leaves each for cutting propagation. After measuring cutting length and diameter, three cuttings were randomly selected from each plant and were put in paper bags and dried at the same conditions mentioned earlier for cutting DW determination. The remaining cuttings from different plots were stuck separately in two 50 -cell $(5 \times 10$ cell $)$ trays containing a fine peat-perlite mix (Sunshine Mix \#5; Sun Gro Horticulture, Agawam, MA). For each tray, half of the cells were used for the cuttings from DL treatment and the other half for those from CL treatment. The two trays were placed in a greenhouse compartment equipped with a misting system for 3-4 weeks. At the end, the number of rooted cuttings (\%), the number of roots per cutting, and the average longest root length $(\mathrm{cm})$ per cutting were determined.

\section{Statistical analysis}

In each experiment, data were subjected to ANOVA using SAS statistical software (University Edition; SAS Institute, Cary, NC) and were presented as means \pm SE. Separations of means for different treatments for each experiment were performed using Tukey's HSD test at a significance level of $P \leq 0.05$, 0.01 , or 0.001 .

\section{Results}

\section{Weekly variation of stock plant growth}

In both experiments, canopy height was generally similar under both treatments at the end of the first lighting stage but increased under DL relative to $\mathrm{CL}$ at the second and final lighting stages (Fig. 2A and B). Under DL relative to $C L$, the number of SBs on the main stem increased at the end of the first lighting stage in both experiments, and remained higher at the end of the second lighting stage in Expt. 1, but showed no difference at the end of the final lighting stage in both experiments (Fig. 2C and D). In Expt. 1,
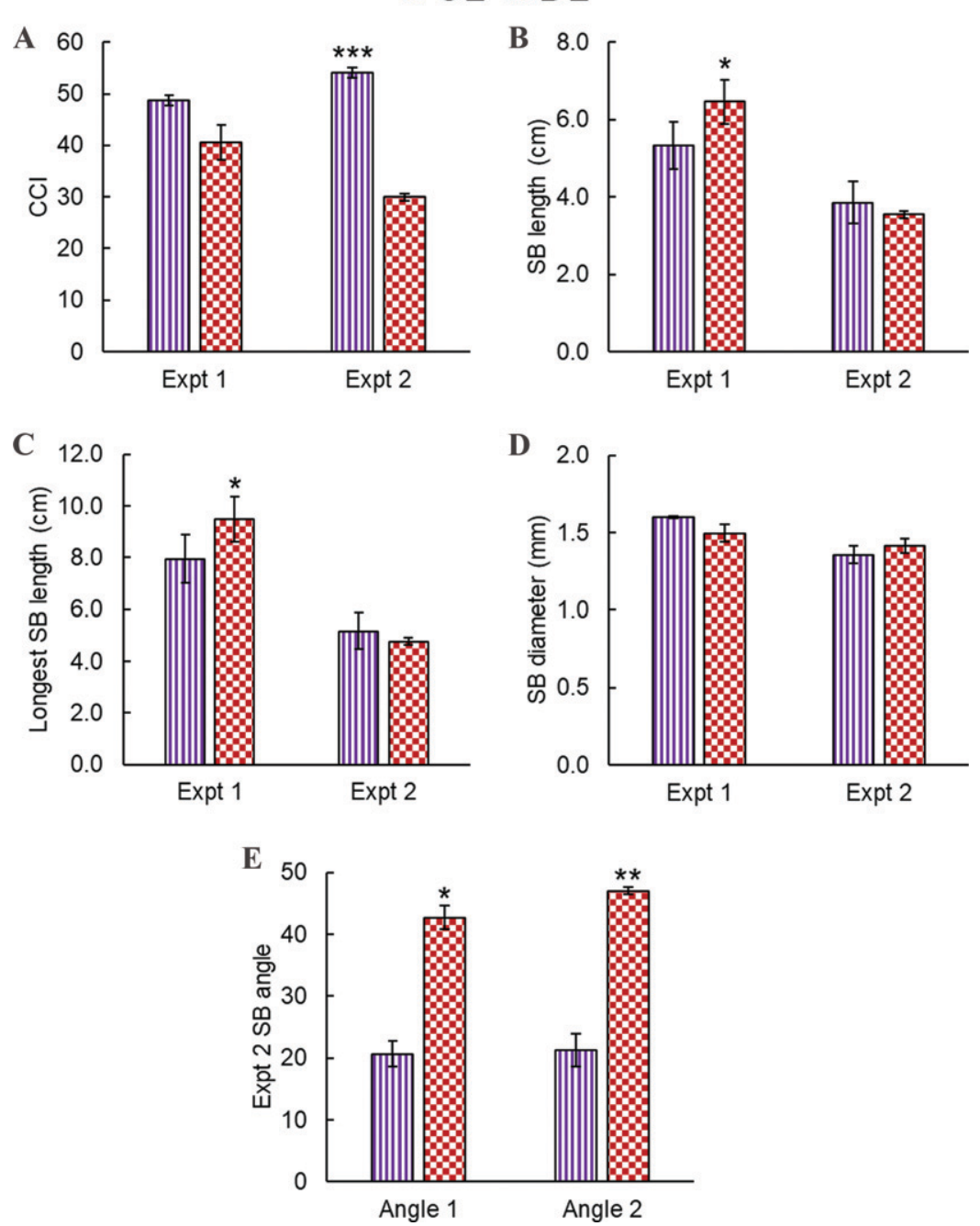

Fig. 3. Campanula stock plant morphology under different lighting treatments. Data are mean $\pm S E(n=3)$. $\mathrm{CCI}=$ chlorophyll content index; $\mathrm{SB}=$ side branch. For the two treatments, $\mathrm{CL}$ was concurrent lighting of red $(85 \%)$ and blue (15\%) light-emitting diodes (LEDs) (RB) at $100 \mu \mathrm{mol} \cdot \mathrm{m}^{-2} \cdot \mathrm{s}^{-1}$, and DL was dynamic lighting of red $\left(170 \mu \mathrm{mol} \cdot \mathrm{m}^{-2} \cdot \mathrm{s}^{-1}\right)$, blue $\left(30 \mu \mathrm{mol} \cdot \mathrm{m}^{-2} \cdot \mathrm{s}^{-1}\right)$, and RB $\left(100 \mu \mathrm{mol} \cdot \mathrm{m}^{-2} \cdot \mathrm{s}^{-1}\right)$ LEDs sequentially at three different lighting stages, respectively. A photoperiod of 24 and $10 \mathrm{~h} \cdot \mathrm{d}^{-1}$ was used for both treatments in Expt. 1 and Expt. 2, respectively. Within each experiment or for all bars in Expt. 2, all bars that have no symbol indicate that the two treatments are not significantly different at $P \leq 0.05$ level, but $*,{ }^{* *}$, or $* * *$ indicate a significant difference at $P \leq 0.05,0.01$, or 0.001 level, respectively, according to Tukey's honestly significant difference test. 
stock plants from both treatments had visible flower buds at time of harvest (5 weeks). After 11 weeks in Expt. 2, no visible flower buds were present under either treatment.

\section{Morphology of stock plants at harvest}

In Expt. 2, leaf CCI was higher under CL than DL, but there was no difference between the two treatments in Expt. 1 (Fig. 3A). In Expt. 1, both SB length and longest SB length were greater under DL than CL, and there was no difference between the two treatments in Expt. 2 (Fig. 3B and C). In both experiments, lighting treatments did not affect the SB diameter (Fig. 3D), as well as the longest SB diameter (data not shown). In Expt. 2, both the inclination angles of SB at two locations were greater under DL than CL (Fig. 3E). In both experiments, lighting treatments did not affect main stem length and diameter, and the lowest and highest SB positions on the main stem (data not shown). In both experiments, lighting treatments did not affect the number of potentially marketable cuttings and the percentage of potentially marketable cuttings relative to total SB number from each stock plant (Supplemental Fig. 1A and B).

\section{Final biomass accumulation of stock plants}

In both experiments, lighting treatments did not affect aboveground DW and total SB DW (Fig. 4A and B). Main stem DW was also unaffected by lighting treatments in Expt. 1 and Expt. 2 (data not shown). In Expt. 2, total DW of SB with one branching order was greater under CL than DL (Fig. 4C), but there was no difference between lighting treatments for total DW of SB with more than one branching order (data not shown).

\section{Morphology, biomass, and rooting of harvested cuttings}

In Expt. 2, lighting treatments did not affect average length, diameter, and DW of individual cuttings, as well as the number of rooted cuttings, the number of roots per cutting, and the average length of the longest root per cutting (Fig. 5A-F).

\section{Discussion}

At the end of the first lighting stage, stock plants under DL produced more SBs than those under CL, despite no difference in SB number per plant at final harvest for cuttings. This reached the goal of the first stage-lighting treatment and confirmed that higher-intensity (170 $\mu \mathrm{mol} \cdot \mathrm{m}^{-2} \cdot \mathrm{s}^{-1}$ ) $\mathrm{R}$ had a greater promotion effect on side branching than lower-intensity $\left(100 \mu \mathrm{mol} \cdot \mathrm{m}^{-2} \cdot \mathrm{s}^{-1}\right) \mathrm{RB}$. However, it took longer ( 8 vs. 2 weeks) to reach the target of the first lighting stage in Expt. 2 than in Expt. 1 because of a decreased DLI from a shorter photoperiod (10 vs. $24 \mathrm{~h} \cdot \mathrm{d}^{-1}$ ). Possibly, besides different light spectra, different DLI also plays an important role in regulating branching, especially when associated with a similarly high PPS value (i.e., around 0.89) for R and RB (Kong et al., 2018; Leduc et al., 2014;
Stutte, 2009). This was also supported by a later catchup of SB number under CL after the second lighting stage, since the intensity (30 vs. $100 \mu \mathrm{mol} \cdot \mathrm{m}^{-2} \cdot \mathrm{s}^{-1}$ ) of the second stage lighting was much lower under DL than CL in addition to lower PPS value (0.49 vs. 0.89 ). The similar SB number under both treatments at final harvest provided a similar number of potentially marketable cuttings per plant if the cuttings were manually harvested one by one from each stock plant (Supplemental Fig. 1).

For machine-harvest of cuttings, each stock plant is cut at a set height once, so final taller stock plants, in addition to more SBs, would be very important to increase the number of potentially marketable cuttings. In both experiments, from the end of the second lighting stage to the final harvest, stock plants grown under DL remained taller compared with CL, and the average stock plant height was above $7.5 \mathrm{~cm}$, a minimal height required for machine-harvest, under DL rather than CL. This indicated that the expected promotion effect on plant height was achieved after using low-intensity B in the second lighting stage. The taller stock plants under DL did not result from longer main stems, but from longer SBs (Expt. 1) or more upright SBs (i.e., greater inclination angle) (Expt. 2). The promoted elongation and hyponasty of SBs is a typical shade-avoidance response to lowintensity B, which has been observed in previous studies on other plant species (Fukuda et al., 2008; Inoue et al., 2008; Kong et al., 2018). Despite increased hyponasty, the elongation of SBs promoted by low-intensity B was not observed in Expt. 2. Possibly, the shorter photoperiod (10 vs. 24 h) in Expt. 2 compared with Expt. 1 could explain the results, since the B-promotion effect is positively related to its lighting exposure time (i.e., photoperiod) (Kong et al., 2019a).

At the end of the final lighting stage, the stock plants under DL compared with CL had similar SB thickness in both experiments and had similar leaf CCI only in Expt. 1. Based on our measurements at the end of the second lighting stage in Expt. 1, DL compared with CL reduced leaf CCI but had similar SB thickness (Supplemental Fig. 2A and B). This indicated that low-intensity B during the second lighting stage caused shade-avoidance responses such as reduced leaf chlorophyll content in addition to promoted plant elongation, which was also supported by previous studies (Kong et al., 2018, 2019b; Nhut et al., 2003). However, 1-week RB-lighting during the final lighting stage can fully recover the leaf greenness at a photoperiod of $24 \mathrm{~h}$ rather than $10 \mathrm{~h}$. Despite the reduced leaf greenness of stock plants at final harvest under DL compared with CL in Expt. 2, the harvested cuttings had similar length and diameter, and subsequent rooting ability. Possibly, for a green cutting with similar stem length and leaf number, stem thickness is more important than leaf chlorophyll content for evaluating cutting quality (Cho et al., 2019; Fischer and Hansen, 1977).

Although DL, compared with CL, increased stock plant height without reducing SB number and thickness or compromising cutting quality, it resulted in some undesirable growth characteristics, such as lower total DW of SB with one branching order and leaf CCI in Expt. 2, rather than in Expt. 1. Possibly, in Expt. 2, a
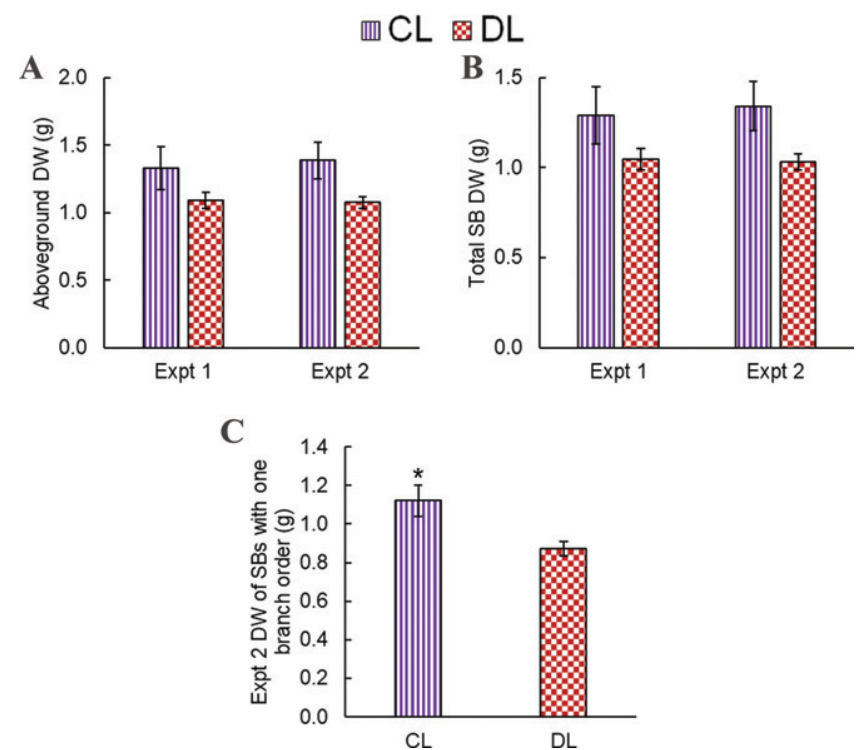

Fig. 4. Campanula stock plant biomass accumulation under different lighting treatments. Data are mean $\pm \mathrm{SE}$ $(\mathrm{n}=3)$. DW = dry weight; $\mathrm{SB}=$ side branch. SBs with one branch order were defined as SBs with no further branching off the SB. For the two treatments, CL was concurrent lighting of red $(85 \%)$ and blue $(15 \%)$ light-emitting diodes (LEDs) (RB) at $100 \mu \mathrm{mol} \cdot \mathrm{m}^{-2} \cdot \mathrm{s}^{-1}$, and DL was dynamic lighting of red $(170$ $\left.\mu \mathrm{mol} \cdot \mathrm{m}^{-2} \cdot \mathrm{s}^{-1}\right)$, blue $\left(30 \mu \mathrm{mol} \cdot \mathrm{m}^{-2} \cdot \mathrm{s}^{-1}\right)$, and $\mathrm{RB}\left(100 \mu \mathrm{mol} \cdot \mathrm{m}^{-2} \cdot \mathrm{s}^{-1}\right)$ LEDs sequentially at three different lighting stages, respectively. A photoperiod of 24 and $10 \mathrm{~h} \cdot \mathrm{d}^{-1}$ was used for both treatments in Expt. 1 and Expt. 2, respectively. Within each experiment or for all bars in Expt. 2, all bars that have no symbol indicate that the two treatments are not significantly different at $P \leq 0.05$ level, but *,**, or *** indicate a significant difference at $P \leq 0.05,0.01$, or 0.001 level, respectively, according to Tukey's honestly significant difference test. 
四CL 图DL
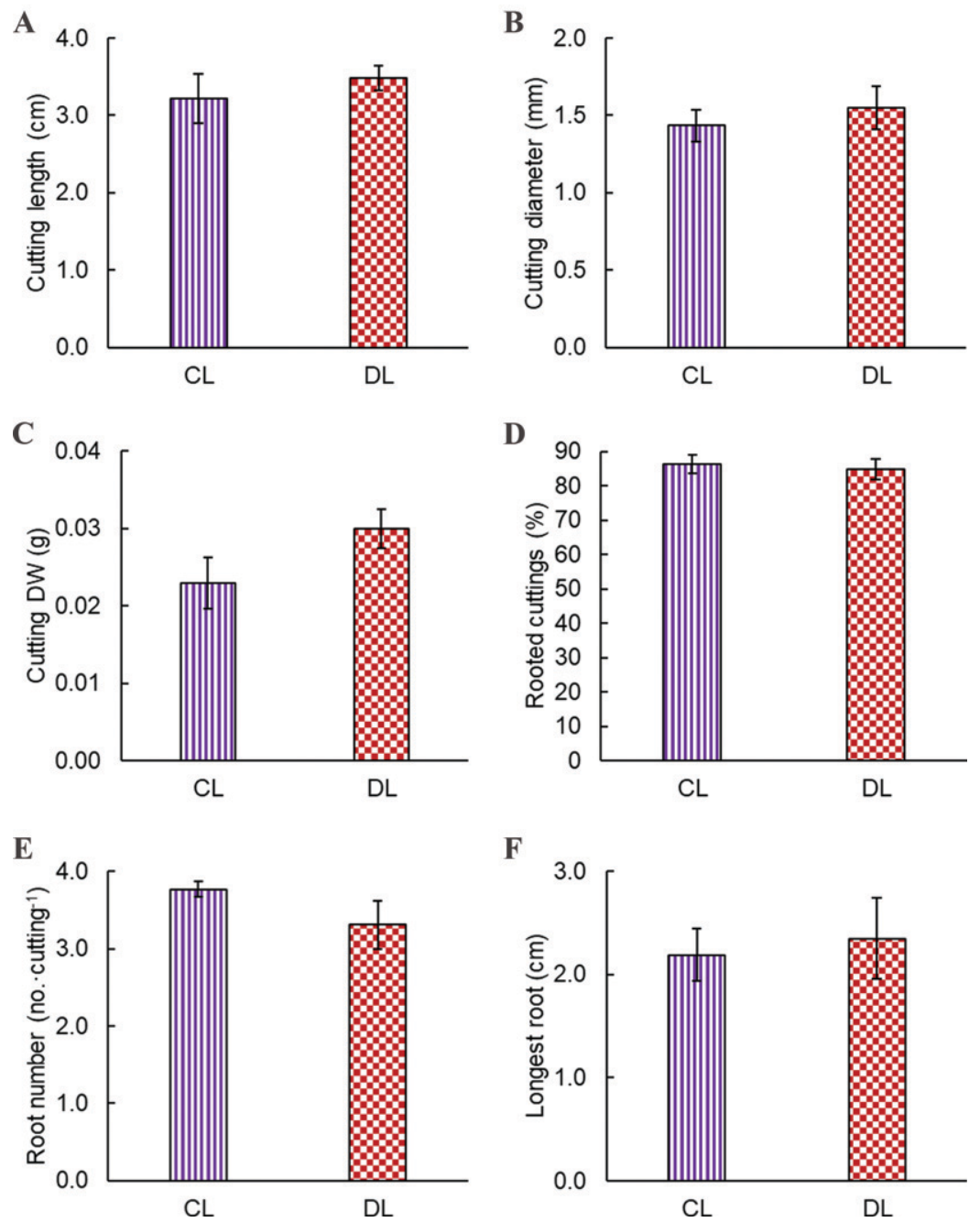

Fig. 5. Morphology, biomass accumulation, and rooting of campanula cuttings under different lighting treatments in Expt. 2. Data are mean $\pm \mathrm{SE}(\mathrm{n}=3)$. $\mathrm{DW}=$ dry weight. For the two treatments, CL was concurrent lighting of red $(85 \%)$ and blue $(15 \%)$ light-emitting diodes (LEDs) (RB) at $100 \mu \mathrm{mol} \cdot \mathrm{m}^{-2} \cdot \mathrm{s}^{-1}$, and DL was dynamic lighting of red $\left(170 \mu \mathrm{mol} \cdot \mathrm{m}^{-2} \cdot \mathrm{s}^{-1}\right)$, blue $\left(30 \mu \mathrm{mol} \cdot \mathrm{m}^{-2} \cdot \mathrm{s}^{-1}\right)$, and RB $\left(100 \mu \mathrm{mol} \cdot \mathrm{m}^{-2} \cdot \mathrm{s}^{-1}\right)$ LEDs sequentially at three different lighting stages, respectively. A photoperiod of $10 \mathrm{~h} \cdot \mathrm{d}^{-1}$ was used for both treatments in Expt. 2. All bars that have no symbol indicate that the two treatments are not significantly different at $P \leq 0.05$ level, but $*, * *$, or $* * *$ indicate a significant difference at $P \leq 0.05,0.01$, or 0.001 level, respectively, according to Tukey's honestly significant difference test.

much longer time ( 8 vs. 2 weeks) of the first stage-lighting with $\mathrm{R}$ alone, compared with Expt. 1, might have negatively affected photosynthetic function, which could not be alleviated by later short (i.e., 3 weeks) lighting time of B and RB. Previous studies have also indicated that plants grown under long duration of $\mathrm{R}$ alone, compared with $\mathrm{RB}$, have lower net photosynthetic rate and leaf chlorophyll content such as in cucumber (Cucumis sativus), strawberry (Fragaria $\times$ ananassa), and tomato (Solanum lycopersicum) (Hogewoning et al., 2010; Nhut et al., 2003; Zhang et al., 2020). The possible decrease in photosynthetic function under DL in Expt. 2 was also supported by another fact that although DL provided more light (i.e., greater light sum; around 386 vs. $282 \mathrm{~mol} \cdot \mathrm{m}^{-2}$ ) than CL (Table 1), the total aerial plant biomass was similar between the two treatments indicating a lower light use efficiency (LUE) (e.g., g.mol ${ }^{-1}$ ) (Supplemental Fig. 3). The greater light sum under DL resulted from the greater $\mathrm{R}$ amount despite a similar B amount compared with CL. It appears that regardless of temporal or spatial combination of $\mathrm{R}$ and $\mathrm{B}$ lighting, proper $\mathrm{R}: \mathrm{B}$ photon flux ratio is necessary to maintain normal photosynthetic function in plants.

In Expt. 1, after 5 weeks of 24-h lighting daily, plants under both treatments showed visible flower buds, which is undesirable for stock plants. The flower buds may affect the rooting of cuttings because of a potential nutritional competition between the two strong sinks (i.e., rooting and flowering) (Hutchinson et al., 2012; Moe, 1976; Walters et al., 2019). In fact, flowering can be regulated by light spectra independent of photoperiod (Putterill et al., 2004; Simpson and Dean, 2002; Thomas, 2006). Our previous study also found that, despite a 24-h photoperiod, R or RB can inhibit flowering in some LDPs such as petunia (Petunia $\times$ hybrida) and calibrachoa (Calibrachoa $\times$ hybrida) compared with B (Kong et al., 2018). However, in Expt. 2, even after 11 weeks at a 10-h photoperiod, visible flower buds did not appear on stock plants under either treatment. Possibly, in the present study, photoperiod is more important than light spectra for flowering of this campanula species, although it is listed as a day-neutral plant rather than a LDP (Whitman and Runkle, 2017).

Despite no visible flower buds on plants in Expt. 2, because of a shortened photoperiod (10 vs. 24-h), the first lighting stage was much longer ( 8 vs. 2 weeks), and the promotion effect of the second stage-lighting on plant (especially SB) elongation was less obvious compared with Expt. 1. Also, DL compared with CL would potentially consume more electrical energy from providing a greater $\mathrm{R}$ light amount and thus greater total light sum in Expt. 2 rather than in Expt. 1 (Table 1). Despite visible flower buds on plants after the three lighting stages in Expt. 1, it was not so at the end of the second lighting stage. At that time in Expt. 1, as mentioned before, DL compared with CL resulted in similar SB thickness despite reduced leaf CCI, which was found to show little negative effects on rooting of the cuttings in Expt. 2. Considering the above information, possibly the final lighting stage is unnecessary for DL when 24-h photoperiod is applied. Also, in Expt. 1, switching from the three-stage lighting to the two-stage lighting could potentially reduce the lighting cost.

In summary, for campanula 'PGM Get $\mathrm{MEE}^{\circledR}$ stock plants grown under SSL, DL increased final canopy height compared with CL under either a 24- or 10-h photoperiod by promoting elongation or hyponasty of SB. At a photoperiod of 24-h, despite promoted elongation of SBs under DL vs. CL, flower buds were visible in stock plants under both treatments at the end. At a photoperiod of 10-h, although DL reduced leaf CCI and total DW of $\mathrm{SB}$ with one branching order in stock plants compared with CL, it did not compromise cutting quality or rooting success. Nevertheless, the DL-increased plant height met the expected target and could benefit future machine harvest in a commercial setting. To further prove the advantage of the DL treatment in terms of economic effectiveness, comparing electricity consumption of the DL and CL treatments is necessary in the future.

\section{Literature Cited}

Adegbola, Y.U., P.R. Fisher, and A.W. Hodges. 2019. Economic evaluation of transplant robots for plant cuttings. Scientia Hort. 246:237-243.

Bergstrand, K.J.I. 2017. Methods for growth regulation of greenhouse produced ornamental potand bedding plants: A current review. Folia Hort. 29:63-74.

Casal, J.J. and M.A. Mazzella. 1998. Conditional synergism between cryptochrome 1 and phytochrome $\mathrm{B}$ is shown by the analysis of phyA, phy $B$, and hy4 simple, double, and triple mutants in Arabidopsis. Plant Physiol. 118:19-25. 
Cho, K.H., V.Y. Laux, N. Wallace-Springer, D.G. Clark, K.M. Folta, and T.A. Colquhoun. 2019. Effects of light quality on vegetative cutting and in vitro propagation of coleus (Plectranthus scutellarioides). HortScience 54:926-935.

Christiaens, A., B. Gobin, and M.C. Van Labeke. 2016. Light quality and adventitious rooting: A mini-review. Acta Hort. 1134:385-393.

Clifford, S.C., E.S. Runkle, F.A. Langton, A. Mead, S.A. Foster, S. Pearson, and R.D. Heins. 2004. Height control of poinsettia using photoselective filters. HortScience 39:383-387.

Craver, J.K., J.K. Boldt, and R.G. Lopez. 2018. Radiation intensity and quality from sole-source light-emitting diodes affect seedling quality and subsequent flowering of long-day bedding plant species. HortScience 53:1407-1415.

Davis, P.A. and C. Burns. 2016. Photobiology in protected horticulture. Food Energy Secur. 5:223-238.

Demotes-Mainard, S., T. Péron, A. Corot, J. Bertheloot, J. Le Gourrierec, S. Pelleschi-Travier, L. Crespel, P. Morel, L. Huché-Thélier, R. Boumaza, A. Vian, V. Guérin, N. Leduc, and S. Sakr. 2016. Plant responses to red and far-red lights: Applications in horticulture. Environ. Exp. Bot. 121:4-21.

Dole, J.M. and J.L. Gibson. 2006. Cutting propagation: A guide to propagating and producing floriculture crops. Ball Publishing, Batavia, IL.

Fischer, P. and J. Hansen. 1977. Rooting of chrysanthemum cuttings: Influence of irradiance during stock plant growth and of decapitation and disbudding of cuttings. Scientia Hort. 7:171-178.

Fukuda, N., M. Fujita, Y. Ohta, S. Sase, S. Nishimura, and H. Ezura. 2008. Directional blue light irradiation triggers epidermal cell elongation of abaxial side resulting in inhibition of leaf epinasty in geranium under red light condition. Scientia Hort. 115:176-182.

Gerovac, J.R., J.K. Craver, J.K. Boldt, and R.G. Lopez. 2016. Light intensity and quality from sole-source light-emitting diodes impact growth, morphology, and nutrient content of Brassica microgreens. HortScience 51:497-503.

Hogewoning, S.W., G. Trouwborst, H. Maljaars, H. Poorter, W. van Ieperen, and J. Harbinson. 2010. Blue light dose-responses of leaf photosynthesis, morphology, and chemical composition of Cucumis sativus grown under different combinations of red and blue light. J. Expt. Bot. 61:3107-3117.

Hutchinson, V.A., C.J. Currey, and R.G. Lopez. 2012. Photosynthetic daily light integral during root development influences subsequent growth and development of several herbaceous annual bedding plants. HortScience 47:856-860.

Inoue, S.I., T. Kinoshita, A. Takemiya, M. Doi, and K.I. Shimazaki. 2008. Leaf positioning of Arabidopsis in response to blue light. Mol. Plant 1:15-26.

Johnson, R.E., Y. Kong, and Y. Zheng. 2020. Elongation growth mediated by blue light varies with light intensities and plant species: A comparison with red light in arugula and mustard seedlings. Environ. Exp. Bot. 169:103898.

Jones-Baumgardt, C., D. Llewellyn, Q. Ying, and Y. Zheng. 2019. Intensity of sole-source lightemitting diodes affects growth, yield, and quality of Brassicaceae microgreens. HortScience 54:1168-1174.
Kim, H.M. and S.J. Hwang. 2019. The growth and development of 'Mini Chal' tomato plug seedlings grown under various wavelengths using light emitting diodes. Agronomy (Basel) 9:1-19.

Kjaer, K.H., C.O. Ottosen, and B.N. Jørgensen. 2011. Cost-efficient light control for production of two campanula species. Scientia Hort. 129:825-831.

Kong, Y., D. Kamath, and Y. Zheng. 2019a. Blue versus red light can promote elongation growth independent of photoperiod: A study in four Brassica microgreens species. HortScience 54:1955-1961.

Kong, Y., K. Schiestel, and Y. Zheng. 2019b. Pure blue light effects on growth and morphology are slightly changed by adding low-level UVA or far-red light: A comparison with red light in four microgreen species. Environ. Exp. Bot. 157:58-68.

Kong, Y., M. Stasiak, M.A. Dixon, and Y. Zheng. 2018. Blue light associated with low phytochrome activity can promote elongation growth as shade-avoidance response: A comparison with red light in four bedding plant species. Environ. Exp. Bot. 155:345-359.

Kong, Y. and Y. Zheng. 2019. Response of growth, yield, and quality of edible-podded snow peas to supplemental LED lighting during winter greenhouse production. Can. J. Plant Sci. 99:676-687.

Kong, Y. and Y. Zheng. 2020. Phototropin is partly involved in blue-light-mediated stem elongation, flower initiation, and leaf expansion: A comparison of phenotypic responses between wild Arabidopsis and its phototropin mutants. Environ. Exp. Bot. 171:103967.

Kuno, Y., H. Shimizu, H. Nakashima, J. Miyasaka, and K. Ohdoi. 2017. Effects of irradiation patterns and light quality of red and blue lightemitting diodes on growth of leaf lettuce ( $\mathrm{Lac}$ tuca sativa L. "Greenwave"). Environ. Control Biol. 55:129-135.

Leduc, N., H. Roman, F. Barbier, T. Péron, L. HuchéThélier, J. Lothier, S. Demotes-Mainard, and S. Sakr. 2014. Light signaling in bud outgrowth and branching in plants. Plants 3:223-250.

Mah, J.J., D. Llewellyn, and Y. Zheng. 2018. Morphology and flowering responses of four bedding plant species to a range of red to far red ratios. HortScience 53:472-478.

McCree, K.J. 1972. The action spectrum, absorptance and quantum yield of photosynthesis in crop plants. Agr. Meteorol. 9:191-216.

Mitchell, C. and G. Stutte. 2017. Sole-source lighting for controlled environment agriculture, p. 48-58. In: R. Lopez and E. Runkle (eds.). Light management in controlled environments. 1st ed. Meister Media Worldwide, Willoughby, $\mathrm{OH}$.

Moe, R. 1976. Environmental effects of stock plants on rooting and further growth of the cuttings of Campanula isophylla Moretti. Acta Hort. 64:71-81.

Moe, R., R.D. Heins, and J. Erwin. 1991. Stem elongation and flowering of the long-day plant Campanula isophylla Moretti in response to day and night temperature alternations and light quality. Scientia Hort. 48:141-151.

Nhut, D.T., T. Takamura, H. Watanabe, K. Okamoto, and M. Tanaka. 2003. Responses of strawberry plantlets cultured in vitro under superbright red and blue light-emitting diodes (LEDs). Plant Cell Tissue Organ Cult. 73:43-52.

Niu, G., R.D. Heins, A. Cameron, and W. Carlson. 2001. Temperature and daily light integral influence plant quality and flower development of Campanula carpatica 'Blue Clips', 'Deep Blue Clips', and Campanula 'Birch Hybrid'. HortScience 36:664-668.

Ohtake, N., M. Ishikura, H. Suzuki, W. Yamori, and E. Goto. 2018. Continuous irradiation with alternating red and blue light enhances plant growth while keeping nutritional quality in lettuce. HortScience 53:1804-1809.

Ouzounis, T., H. Giday, K.H. Kjaer, and C.O Ottosen. 2018. LED or HPS in ornamentals: A case study in roses and campanulas. Eur. J. Hort. Sci. 83:166-172.

Ouzounis, T., X. Fretté, E. Rosenqvist, and C.O. Ottosen. 2014. Spectral effects of supplementary lighting on the secondary metabolites in roses, chrysanthemums, and campanulas. J. Plant Physiol. 171:1491-1499.

Putterill, J., R. Laurie, and R. Macknight. 2004. It's time to flower: The genetic control of flowering time. BioEssays 26:363-373.

Randall, W.C. and R.G. Lopez. 2014. Comparison of supplemental lighting from high-pressure sodium lamps and light-emitting diodes during bedding plant seedling production. HortScience 49:589-595.

Randall, W.C. and R.G. Lopez. 2015. Comparison of bedding plant seedlings grown under sole-source light-emitting diodes (LEDs) and greenhouse supplemental lighting from LEDs and high-pressure sodium lamps. HortScience 50:705-713.

Shimokawa, A., Y. Tonooka, M. Matsumoto, H. Ara, H. Suzuki, N. Yamauchi, and M. Shigyo. 2014. Effect of alternating red and blue light irradiation generated by light emitting diodes on the growth of leaf lettuce. bioRxiv.

Simpson, G.G. and C. Dean. 2002. Arabidopsis: The Rosetta stone of flowering time? Science 296:285-289.

Stutte, G.W. 2009. Light-emitting diodes for manipulating the phytochrome apparatus. HortScience 44:231-234

Sysoeva, M.I., E.F. Markovskaya, and T.G. Shibaeva. 2010. Plants under continuous light: A review. Plant Stress 4:5-17.

Thomas, B. 2006. Light signals and flowering. J. Expt. Bot. 57:3387-3393.

Walters, K.J., A.A. Hurt, and R.G. Lopez. 2019. Flowering, stem extension growth, and cutting yield of foliage annuals in response to photoperiod. HortScience 54:661-666.

Whitman, C. and E. Runkle. 2017. Light and herbaceous perennials, p. 135-145. In: R. Lopez and E. Runkle (eds.). Light management in controlled environments. 1st ed. Meister Media Worldwide, Willoughby, $\mathrm{OH}$.

Zhang, Y., E. Kaiser, Y. Zhang, J. Zou, Z. Bian, Q. Yang, and T. Li. 2020. UVA radiation promotes tomato growth through morphological adaptation leading to increased light interception. Environ. Exp. Bot. 176:104073.

Zheng, Y. 2016. Are LEDs the right choice for my operation? Greenhouse Canada, March/April Issue, p. 14-18. < https://www.greenhousecanada. com/structures-equipment/lighting/are-leds-theright-choice-for-my-operation-30969>. 

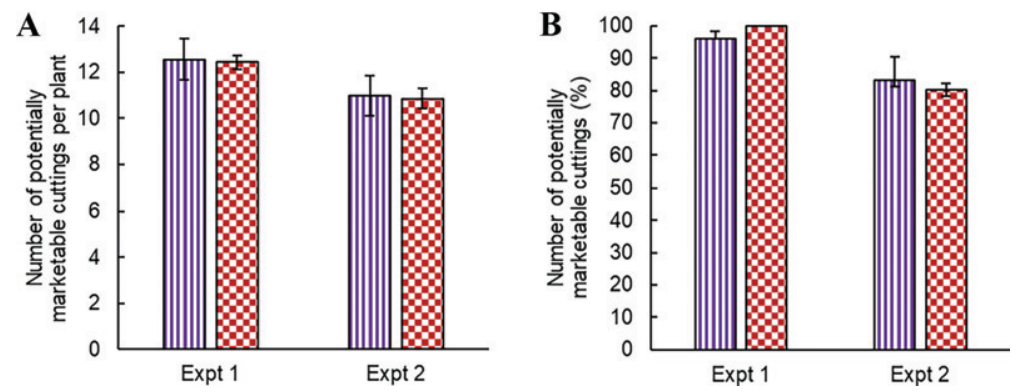

Supplemental Fig. 1. Campanula stock plant morphology under different lighting treatments. Data are mean $\pm \mathrm{SE}(\mathrm{n}=3)$. For the two treatments, CL was concurrent lighting of red (85\%) and blue (15\%) light-emitting diodes (LEDs) (RB) at $100 \mu \mathrm{mol} \cdot \mathrm{m}^{-2} \cdot \mathrm{s}^{-1}$, and DL was dynamic lighting of red (170 $\left.\mu \mathrm{mol} \cdot \mathrm{m}^{-2} \cdot \mathrm{s}^{-1}\right)$, blue $\left(30 \mu \mathrm{mol} \cdot \mathrm{m}^{-2} \cdot \mathrm{s}^{-1}\right)$, and RB $\left(100 \mu \mathrm{mol} \cdot \mathrm{m}^{-2} \cdot \mathrm{s}^{-1}\right)$ LEDs sequentially at three different lighting stages, respectively. A photoperiod of 24 and $10 \mathrm{~h} \cdot \mathrm{d}^{-1}$ was used for both treatments in Expt. 1 and Expt. 2, respectively. Within each experiment, all bars that have no symbol indicate that the two treatments are not significantly different at $P \leq 0.05$ level, but *, **, or *** indicate a significant difference at $P \leq 0.05,0.01$, or 0.001 level, respectively, according to Tukey's honestly significant difference test.

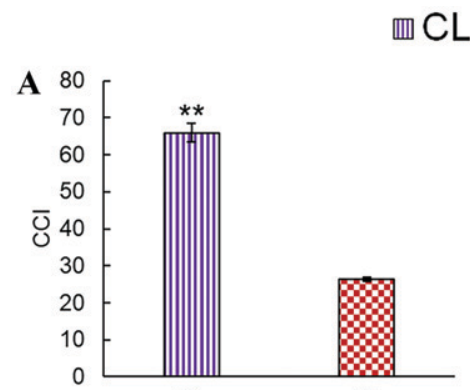

$\mathrm{CL}$

DL

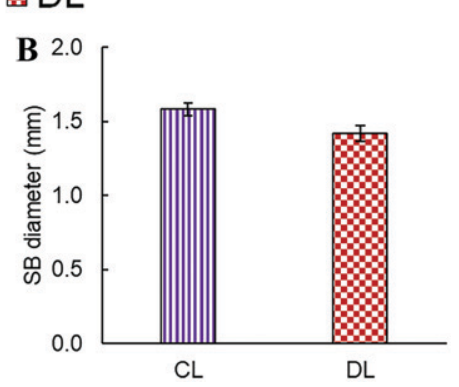

Supplemental Fig. 2. Campanula stock plant morphology under different lighting treatments at the end of the second lighting stage in Expt. 1. Data are mean \pm $\mathrm{SE}(\mathrm{n}=3)$. $\mathrm{CCI}=$ chlorophyll content index; $\mathrm{SB}=$ side branch. For the two treatments, $\mathrm{CL}$ was concurrent lighting of red $(85 \%)$ and blue $(15 \%)$ lightemitting diodes (LEDs) (RB) at $100 \mu \mathrm{mol} \cdot \mathrm{m}^{-2} \cdot \mathrm{s}^{-1}$, and DL was dynamic lighting of red $\left(170 \mu \mathrm{mol} \cdot \mathrm{m}^{-2} \cdot \mathrm{s}^{-1}\right)$, blue $\left(30 \mu \mathrm{mol} \cdot \mathrm{m}^{-2} \cdot \mathrm{s}^{-1}\right)$, and RB $(100$ $\mu \mathrm{mol} \cdot \mathrm{m}^{-2} \cdot \mathrm{s}^{-1}$ ) LEDs sequentially at three different lighting stages, respectively. A photoperiod of $24 \mathrm{~h} \cdot \mathrm{d}^{-1}$ was used for both treatments in Expt. 1 . All bars that have no symbol indicate that the two treatments are not significantly different at $P \leq 0.05$ level, but $*, * *$, or *** indicate a significant difference at $P \leq 0.05,0.01$, or 0.001 level, respectively, according to Tukey's honestly significant difference test.

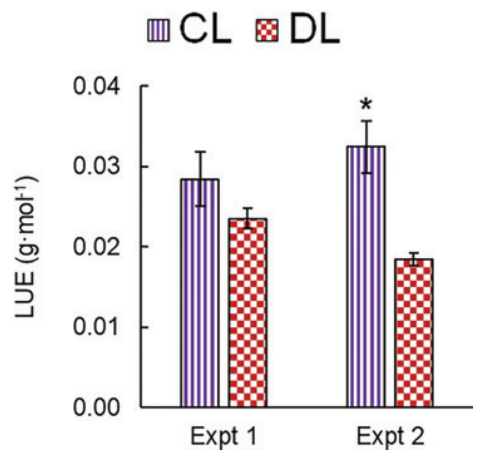

Supplemental Fig. 3. Light use efficiency (LUE; $g \cdot \mathrm{mol}^{-1}$ ) of campanula stock plants under different lighting treatments. Data are mean $\pm \mathrm{SE}(\mathrm{n}=3$ ). For the two treatments, CL was concurrent lighting of red $(85 \%)$ and blue $(15 \%)$ light-emitting diodes (LEDs) (RB) at $100 \mu \mathrm{mol} \cdot \mathrm{m}^{-2} \cdot \mathrm{s}^{-1}$, and DL was dynamic lighting of red $\left(170 \mu \mathrm{mol} \cdot \mathrm{m}^{-2} \cdot \mathrm{s}^{-1}\right)$, blue $\left(30 \mu \mathrm{mol} \cdot \mathrm{m}^{-2} \cdot \mathrm{s}^{-1}\right)$, and $\mathrm{RB}\left(100 \mu \mathrm{mol} \cdot \mathrm{m}^{-2} \cdot \mathrm{s}^{-1}\right)$ LEDs sequentially at three different lighting stages, respectively. A photoperiod of 24 and $10 \mathrm{~h} \cdot \mathrm{d}^{-1}$ was used for both treatments in Expt. 1 and Expt. 2, respectively. Within each experiment, all bars that have no symbol indicate that the two treatments are not significantly different at $P \leq 0.05$ level, but $*, * *$, or $* * *$ indicate a significant difference at $P \leq 0.05$, 0.01 , or 0.001 level, respectively, according to Tukey's honestly significant difference test. 